\title{
ORFEUS Services for Coordinated High-Quality Seismic Waveform Data Access in Pan-Europe
}

\section{Other Conference Item}

\section{Author(s):}

Cauzzi, Carlo Virgilio (D); Bieńkowski, Jarek; Custódio, Susana; Evangelidis, Christos; Guéguen, Philippe; Haberland, Christian; Haslinger, Florian (D); Lanzano, Giovanni; Meier, Thomas; Michelini, Alberto; Ottemöller, Lars; Pedersen, Helle; Quinteros, Javier; Sleeman, Reinoud; Strollo, Angelo; Trani, Luca

\section{Publication date:}

2021

\section{Permanent link:}

https://doi.org/10.3929/ethz-b-000464291

\section{Rights / license:}

Creative Commons Attribution 4.0 International

\section{Originally published in:}

EGU General Assembly 2020, https://doi.org/10.5194/egusphere-egu2020-8389 
EGU2020-8389, updated on 25 Feb 2021

https://doi.org/10.5194/egusphere-egu2020-8389

EGU General Assembly 2020

(c) Author(s) 2021. This work is distributed under

the Creative Commons Attribution 4.0 License.

\section{ORFEUS Services for Coordinated High-Quality Seismic Waveform Data Access in Pan-Europe}

Carlo Cauzzi ${ }^{1}$, Jarek Bieńkowski ${ }^{10}$, Susana Custódio ${ }^{2}$, Christos Evangelidis ${ }^{3}$, Philippe Guéguen ${ }^{4}$, Christian Haberland ${ }^{5}$, Florian Haslinger ${ }^{6}$, Giovanni Lanzano ${ }^{7}$, Thomas Meier ${ }^{8}$, Alberto Michelini ${ }^{12}$, Lars Ottemöller ${ }^{9}$, Helle Pedersen ${ }^{4}$, Javier Quinteros ${ }^{11}$, Reinoud Sleeman ${ }^{10}$, Angelo Strollo ${ }^{11}$, and Luca Trani ${ }^{10}$

'ORFEUS and Swiss Seismological Service (SED) at ETH Zürich, Switzerland (carlo.cauzzi@sed.ethz.ch)

${ }^{2}$ Instituto Dom Luiz (IDL), Faculty of Sciences of the University of Lisbon (FCUL), Portugal

${ }^{3}$ Institute of Geodynamics, National Observatory of Athens (NOA-IG), Greece

${ }^{4}$ Institut des Sciences de la Terre (ISTerre), Université Grenoble Alpes (UGA), France

${ }^{5}$ Geophysical Deep Sounding Section, German Research Centre for Geosciences (GFZ), Potsdam

${ }^{6}$ EPOS Seismology and Swiss Seismological Service (SED) at ETH Zürich, Switzerland

${ }^{7}$ Istituto Nazionale di Geofisica e Vulcanologia (INGV), Milan, Italy

${ }^{8}$ Institute for Geosciences, Christian-Albrechts University of Kiel, Germany

${ }^{9}$ Department of Earth Science, University of Bergen (UiB), Norway

${ }^{10}$ ORFEUS Data Center (ODC) and Royal Netherlands Meteorological Institute (KNMI), De Bilt

${ }^{11}$ Seismology Section, German Research Centre for Geosciences (GFZ), Potsdam

${ }^{12}$ Istituto Nazionale di Geofisica e Vulcanologia (INGV), Rome, Italy

ORFEUS (Observatories and Research Facilities for European Seismology) is a non-profit foundation that promotes seismology in the Euro-Mediterranean area through the collection, archival and distribution of seismic waveform data, metadata and closely related products. The data and services are collected or developed at national level by more than 60 contributing Institutions in Pan-Europe and further developed, integrated, standardized, homogenized and promoted through ORFEUS. Among the goals of ORFEUS are: (a) the development and coordination of waveform data products; (b) the coordination of a European data distribution system, and the support for seismic networks in archiving and exchanging digital seismic waveform data; (c) the encouragement of the adoption of best practices for seismic network operation, data quality control and data management; (d) the promotion of open access to seismic waveform data, products and services for the broader Earth science community. These goals are achieved through the development and maintenance of services targeted to a broad community of seismological data users, ranging from earth scientists to earthquake engineering practitioners. Two Service Management Committees (SMCs) are consolidated within ORFEUS devoted to managing, operating and developing (with the support of one or more Infrastructure Development Groups): (i) the European Integrated waveform Data Archive (EIDA; https://www.orfeuseu.org/data/eida/); and (ii) the European Strong-Motion databases (SM; https://www.orfeuseu.org/data/strong/). A new SMC is being formed to represent the community of European mobile 
pools. Products and services for computational seismologists are also considered for integration in the ORFEUS domain. ORFEUS services currently provide access to the waveforms acquired by 10,000 stations in Pan-Europe, including dense temporary experiments, with strong emphasis on open, high-quality data. Contributing to ORFEUS data archives means long-term archival, state-ofthe-art quality control, improved access and increased usage. Access to data and products is ensured through state-of-the-art information and communications technologies, with strong emphasis on federated web services that considerably improve seamless user access to data gathered and/or distributed by ORFEUS institutions. The web services also facilitate the automation of downstream products. Particular attention is paid to adopting clear policies and licences, and acknowledging the crucial role played by data providers / owners, who are part of the ORFEUS community. There are significant efforts by ORFEUS participating Institutions to enhance the existing services to tackle the challenges posed by the Big Data Era, with emphasis on data quality, improved user experience, and implementation of strategies for scalability, high-volume data access and archival. ORFEUS data and services are assessed and improved through the technical and scientific feedback of a User Advisory Group (UAG), comprised of European Earth scientists with expertise encompassing a broad range of disciplines. All ORFEUS services are developed in coordination with EPOS and are largely integrated in the EPOS Data Access Portal. ORFEUS is one of the founding Parties and fundamental pillars of EPOS Seismology. This contribution presents the current products and services of ORFEUS and introduces the planned key future activities. We aim at stimulating Community feedback about the current and planned ORFEUS strategies. 